\title{
Incidência de mastite subclínica em rebanho leiteiro no interior do estado de São Paulo
}

Juan Felipe Mata Jurca, Daniela Junqueira de Queiroz ${ }^{[a, b]^{*}}$, Mayara Gonçalves Fonseca ${ }^{[b]}$, Tainá Caroline Beletti Valente Silva ${ }^{[a]}$ Fabio José Menezes dos Santos ${ }^{[a]}$ Thiago Correa Neves de Souza ${ }^{[]]}$, Deborah Penteado Martins Dias ${ }^{[a]}$, Maria da Graça Portantiolo Corrêa ${ }^{[c]}$, Fernanda Pavinatto Toro ${ }^{[c]}$, Inivaldo Corrêa ${ }^{[c]}$

\footnotetext{
[a] Centro Universitário Barão de Mauá (CBM), Ribeirão Preto, SP, Brasil

${ }^{[b]}$ Faculdade de Ciências Agrárias e Veterinárias, Universidade Estadual Paulista (UNESP), Jaboticabal, SP, Brasil

${ }^{[c]}$ Laboratório Vitafort Indústria e Comércio de Produtos Veterinários Ltda, Ribeirão Preto, SP, Brasil
}

*Autor correspondente

e-mail: danielajqueiroz@hotmail.com

\section{Resumo}

A mastite é um dos principais problemas sanitários da pecuária leiteira e a principal causa de perdas econômicas, além de causar danos à saúde pública pela veiculação de microrganismos e toxinas no leite. Assim, objetivou-se mostrar a incidência de mastite subclínica em um rebanho leiteiro de vacas holandesas do interior do estado de São Paulo. Para tanto, coletou-se leite dos quatro quartos mamários das 229 vacas em lactação pertencentes à propriedade estudada. As amostras de leite, compostas por secreção dos quatro quartos mamários, foram coletadas em copo coletor acoplado ao sistema de ordenha e armazenadas em frascos contendo bromopol para contagem de células somáticas (CCS) e coletadas diretamente do úbere do animal em frascos esterilizados para realização de exame microbiológico. A CCS foi realizada na Clínica do Leite - Esalq/ USP - Piracicaba/SP em aparelho de citometria de fluxo, e as análises microbiológicas no Laboratório Vitafort Indústria e Comércio de Produtos Veterinários Ltda - Ribeirão Preto/SP. Das 229 amostras coletadas, observou-se crescimento de microrganismos em 84 (36,68\%) e as outras 145 (63,32\%) foram negativas no exame microbiológico. Considerando-se que a prevalência de mastite subclínica em uma propriedade não deve ultrapassar 15\%, no presente estudo a incidência foi alta. Ademais, em 43 (51,2\%) amostras isolou-se apenas um agente etiológico e nas outras $41(48,8 \%)$ foram isolados dois ou três agentes simultaneamente. Quanto aos microrganismos encontrados, o gênero Staphylococcus foi o mais prevalente (50\%), seguido por Streptococcus (34,5\%), Enterobacter (14,3\%), leveduras (14,3\%), Escherichia coli (9,5\%), Salmonella (8,3\%), Proteus (7,1\%), Citrobacter (4,8\%), Pseudomonas (4,8\%), outras bactérias Gram negativas (2,4\%), Serratia (1,2\%) e Shigella (1,2\%). Os resultados obtidos corroboram os dados da literatura, que trazem Staphylococcus e Streptococcus como os principais causadores de mastites bovinas. Em relação 
à CCS, a média de células somáticas das amostras analisadas foi de 415 células. Diante desses resultados, conclui-se que tanto o manejo e a higiene ambiental quanto o emprego de solução desinfetante antes e após a ordenha (pré-dipping e pós-dipping) devem ser revistos a fim de controlar agentes ambientais e contagiosos envolvidos nos quadros de mastite subclínica. 